Article

\title{
The Priority Given to Sustainability by Industrial Designers within an Industry 4.0 Paradigm
}

\author{
Blair Kuys *(D), Christoph Koch (D) and Gianni Renda (D) \\ Centre for Design Innovation, School of Design and Architecture, Swinburne University of Technology, \\ Melbourne 3122, Australia; ckoch@swin.edu.au (C.K.); grenda@swin.edu.au (G.R.) \\ * Correspondence: bkuys@swin.edu.au
}

\begin{abstract}
Industrial design is intrinsically linked to manufacturing; however, what is required of industrial design to adapt to new changes brought on by Industry 4.0 in manufacturing is unknown. Current literature gives little insight into how industrial designers need to evolve to the current developments in manufacturing to remain value drivers in an Industry 4.0 paradigm. There is minimal research describing the link between industrial design, Industry 4.0 and the effect this will have on sustainability. We conducted an extensive survey of 190 respondents from 53 countries to establish the present state of industrial design practice globally and to better understand the priority sustainability is given by practicing industrial designers. Qualitative data showed a desire for improved sustainable processes; however, quantitative data contradicted this, showing "sustainability" as one of the lowest ranked areas of importance in design practice for industrial designers. While sustainability—especially in manufacturing—demands more prominent change as industrial design adapts to an Industry 4.0 manufacturing paradigm, it seems that junior industrial designers do not currently see this as a priority.
\end{abstract}

Keywords: industrial design; Industry 4.0; sustainability; manufacturing; priority; value; sustainable

check for

updates

Citation: Kuys, B.; Koch, C.; Renda, G. The Priority Given to Sustainability by Industrial Designers within an Industry 4.0 Paradigm. Sustainability 2022, 14, 76. https:// doi.org/10.3390/su14010076

Academic Editor: Barbara Motyl

Received: 4 November 2021

Accepted: 18 December 2021

Published: 22 December 2021

Publisher's Note: MDPI stays neutral with regard to jurisdictional claims in published maps and institutional affiliations.

Copyright: (c) 2021 by the authors. Licensee MDPI, Basel, Switzerland. This article is an open access article distributed under the terms and conditions of the Creative Commons Attribution (CC BY) license (https:// creativecommons.org/licenses/by/ $4.0 /)$.

\section{Introduction}

Establishing close relationships or close partnerships with manufacturers is one way that industrial designers can stay abreast with manufacturing change. It is also an enabler for designers to influence manufacturers to be more innovative, more sustainable and more flexible when working with designers. In the eyes of industrial designers, the aspect of sustainability is not only concerned with ecological issues but also with economic sustainability. However, industrial designers are of the belief that the barrier to be more "sustainable" seems to rest with profit-driven manufacturers. There are existing frameworks showing how to integrate Industry 4.0 alongside sustainability practices into a company [1-3]; however, the role of the industrial designer in the process of integration is largely neglected. Although "design" is mentioned in previous literature on this topic, the designers themselves are not included. The survey conducted for this study took the perspectives of practicing industrial designers rather than company managers, and a knowledge gap was apparent when a number of industrial design respondents were unfamiliar with existing frameworks. This study is exploratory and shows that industrial designers need to better understand existing frameworks for Industry 4.0 and sustainable integration to be a driving force in this manufacturing paradigm. This research reveals that it is the systems that surround the manufacturing procedures that are crucial to both ecological and economic sustainability, not only the methods of production themselves, and it is the designer who needs to evolve to design for an Industry 4.0 manufacturing environment. Industrial designers support future manufacturing to be more sustainable; however, current practice suggests this is not the highest priority when designing.

Much of the existing literature within sustainability for Industry 4.0 focuses on the overall manufacturing environment, focusing on a circular economy of supply. Little is 
discussed in detail about the choices made during the conceptual stage when products are initially designed; this key issue forms one of the main points in our study.

\section{Aim and Objective}

The aim of this paper is to investigate how - and what - a meaningful relationship between industrial designers and manufacturers may look similar to in an Industry 4.0 context. Our study surveyed industrial designers globally to understand their position on how they engage with Industry 4.0, as this specific area has been understudied. While the authors acknowledge that within the Industry 4.0 landscape, manufacturing and supply-chain processes are the foci of most research; fundamentally, the role of those processes is to support the production of an object to be purchased and used by a consumer. Through better understanding the involvement of the designer, future efficiencies and better collaborations may be found, resulting in more sustainable outcomes both ecologically and economically. The objective is to provide context from a designer's perspective as to how sustainability is prioritised and what needs to change as industrial design evolves alongside Industry 4.0. This paper establishes a context, but also provides a guide for which global regions may require further education and awareness for sustainable design and manufacturing practices.

\section{Literature Review}

The literature search focused on different outlooks on the future of the industrial design profession, with specific attention to industrial design's link with manufacturing and sustainability issues that arise. [4] mentioned a potential "crisis to the otherwise stable areas of design practice" through Industry 4.0 changes to manufacturing. Reference [5] elaborates that if designers fail to adapt to these developments, "new competencies will emerge to fill the gap left behind". Since design is closely linked and associated with technology [6] and these technologies are constantly evolving, thus does design [7]. As seen from past research related to the design profession, [4] predicts that industrial design will "mutate" again as it did concurrently with the changes it faced during the 20th century. Reference [8] asks important questions about the meaning of being a designer in the future with concepts such as design networks or open design, and what they will signify for the professional designer if, and when, everybody designs [9]. Therefore, defining industrial design's core values and manufacturing engagement and the impact this has on being a more sustainable designer helps in determining and futureproofing the profession for the changes Industry 4.0 will bring.

The research presented in this paper is significant for the field of industrial design in highlighting issues in the current state of the product/industrial design practice, as well as understanding the core competencies-and potential areas for improvement-designers require to better prepare themselves for the fourth industrial revolution. The literature identified that the voice of the industrial designer is not prominent, despite the designer being one of the major "actors" in the creation of new products. Reference [6] claimed early on that "design is changing; its products and processes are changing, so too is the role demanded of the designer". This continues to remain true and presents opportunities to create new product development strategies within an Industry 4.0 paradigm, and for industrial design to remain as a value driver and sustainable contributor in a manufacturing environment [10]. Since design is a vital part of supporting a manufacturing enterprise [11], it is important for industrial designers to understand the changes and opportunities Industry 4.0 presents.

In their handbook [12], the authors split industrial design up into different chapters, i.e.,:

- $\quad$ design in the context of business;

- design and manufacturing processes;

- intellectual property;

- ergonomics;

- $\quad$ sustainability; 
- design documentation, etc.

There is a stark difference between what industrial designers do versus what they achieve within product development. The contemporary industrial design definitions are primarily outcome focussed, and do not touch on tacit processes designers employ to achieve physical outcomes. Although these "outside" definitions portray industrial design's strengths they fail to show the whole picture. The understanding of sustainability as an essential value, results from a coming to consciousness in the field of engineering and design [13,14]. The author of [13], who wrote a seminal article published in Design Issues, Design for a Sustainable World, argues for change:

Design will change through a coming to consciousness of its individual practitioners. Broad proposals and visions are a stimulus to this process but cannot replace the hard sustained work of rethinking one's identity as a professional. What makes this process so essential right now is the clear evidence that older models of practice are not working. [13]

Ref. [6] already predicted "post-industrial design", which in contrast to the conventional non-hierarchical design processes, rather than an autocratic process, sees the product development approach being more transparent and interdisciplinary. Current design practice, however, is still concerned with developing specialised and mass manufactured goods, which are designed for short-term profitability [6]. In contrast, post-industrial design, according to [6], will be a more flexible and inclusive process compared to the more rigid industrial design processes of today. This means the incorporation of a more democratic structure, which is participatory and open to everyone, and which also takes into account the needs of the environment and society into the broader design process [6]. This is further expanded by [15], demonstrating how the end-of-life of a product is considered at the point of product's conception, certainly a significant evolution from the earlier definition by [6].

Ref. [6] elaborates that post-industrial products ideally might be more generalised, multipurpose tools which are designed to be long-lasting, repairable and more sustainable, while also suggesting that the properties of these post-industrial products will be short-run and customised rather than mass-produced and standardised. Certainly, with the advent of 3D printing and online bureaux that provide these services [16], there is truth to this, however, it is the former point that [6] made that has become prescient. Reference [3] details a commonly held principle in how a product is considered for production within an Industry 4.0 environment, with six key areas identified: interoperability, virtualisation, decentralisation, real-time capability, service orientation, modularity, and finally, eco-design. Ensuring that meaningful engagement with these six areas-and in particular, eco-design - is the challenge for the modern industrial designer, ensuring that the product is outwardly sustainable from its onset, i.e., designed in the spirit of repairability, that it is long lasting, and so on. This becomes somewhat complex when we consider [5], adding that industrial designers will have to balance two extremes: global "super mass-production" and "product customisation", which satisfy the customer's needs on an individual level [17]. The latter prediction became especially clear with the emergence of Industry 4.0s concept of "mass customisation" [18]. Since technologies in and for manufacturing is rapidly advancing, such does the designer's role have to adjust to these ever-ongoing changes $[5,6,19]$.

"Should designers fail to adapt, new competencies will emerge to fill the gap left behind" [5]. Knowledge is still developing and growing, and it will continue to do so until it is transformed into multiple knowledges [20]. Especially the ever-growing and complex field of industrial design that can be described by multiple knowledges [20]. This concept goes back to design itself being an interdisciplinary field [21,22]. Therefore, it can be argued, that when knowledge in a certain field becomes too complex and too abundant, the field will evolve or diverge into other specialised professions [20].

Currently, industrial designers are involved in more than the design of physical products (e.g., form giving) [4], due to the considerable expansion of the application of the design field in recent times [20]. With the introduction of innovative approaches and 
technologies into the design world in the late 20th century, industrial design activity got increasingly complex [23]. Designers are now engaged in a multitude of diverse activities such as user experience (UX) and user interaction (UI) design as well as service design fitting within the design skillset [20]. "The rapid development of these areas is, in part, propelled by a broad recognition of design thinking and practice as a significant driver of innovation" [20].

Within an Industry 4.0 context, sustainability is one of the key drivers, however this is in a more general manner. For instance, Ref. [24] details processes within the overall manufacturing environment and supply chain, however the initial concepts appear to not be discussed with a designer. While the authors of this paper accept that in this particular case, the product being discussed are ceramic tiles and a designer's input may be limited, it is of note that this journal's most cited paper is one of life-cycle assessment [25], which indicates an underlying interest and importance of sustainably conceptualised and carefully designed products - all of which are within the remit of a professionally trained industrial designer. Ref. [26] states that sustainability value within an organisation is commonly understood as monetary value; however, sustainability requires a more comprehensive view of value that includes social and environmental benefits [27]. For this study, the "value" of sustainability is apparent when economic, social and environmental value is effectively integrated into business models that are maturing within an Industry 4.0 manufacturing paradigm. We propose that sustainable value must be integrated with the same level of priority alongside other sources of value (social, cultural and economic), as companies adapt to Industry 4.0.

While the authors of this paper do not discount the importance of an overall viewpoint of sustainability within Industry 4.0, they advocate for greater involvement at the briefing stage. Referring to [15] by engaging with the stakeholders involved within an early stage (i.e., manufacturer, client, user), sustainability aspects of the project, which involve raw materials, supply chains, overall durability of the finished product, as well as aesthetics, were able to be enhanced through strong collaboration. It is this factor in particular that is of interest to the authors of this study and was subsequently investigated.

\section{Method}

A global survey was conducted in 2020 consisting of 30 questions to better understand the current state of industrial design and its link to Industry 4.0. The survey questions for this research were developed from a pilot study consisting of six practising industrial designers (three male, three female), providing an immediate instrument for developing the survey. Detailed information of this pilot study was presented at the Design Research Society (DRS) conference in 2020 and published in the subsequent proceedings (refer to [28]). The overarching theory was a mixed methods approach where qualitative research from the focus group was used to inform the quantitative survey presented in this paper. The basis of the survey was formulated using the existing literature on industrial design to establish the present state of industrial design practice globally and to identify areas for improvement, as well as opportunities for growth within the discipline. This approach helped define and communicate the capabilities and priority of industrial design for future manufacturing industries and gauge the state of sustainable design within this new paradigm.

The number of people who were contacted to complete this survey was estimated at around 1700 . The response rate was 18 per cent, with an initial sample of 307 respondents collected after four months of running the survey. However, not all data were used in the analysis. After multiple screenings during coding, some answers were excluded under certain conditions:

- Incomplete surveys;

- Contributed by repeated respondents;

- Unusual data inputs (outliers) which may be falsified or are misleading;

- Invalid responses due to language barriers. 
Removing these outliers was important in mitigating bias and errors in the statistical analysis. The remaining sample size after the data clean-up ended with a total of 190 completed surveys, specifically from product/industrial design globally. The dominant specialisation was general product design, followed by furniture/lighting design, automotive/transportation design, and lastly, systems and service design. This large sample size was important to gain a greater understanding of the industrial design profession globally and the priority given to sustainability. The open-ended follow-up questions were subsequently checked for language accuracy and non-English answers translated with Google Translator. Some of the languages which needed to be translated were Korean, Mandarin and Spanish. The original data entries in these languages were preserved with an English translation attached.

The online survey was conducted in line with the National Statement on Ethical Conduct in Human Research and was approved in May 2019. All respondent's data in the survey were anonymised or was anonymous from the beginning since no signifiers were used. The respondents agreed to undertake the study based on the informed consent statement at the commencement of the survey and, as such, gave consent for the data to be used for this research. Following is a summary of the demographics and experience:

The 190 product/industrial designers who completed the survey were between the ages of 18-64. In total, 57.4 per cent of the respondents was in the age bracket of 25-34 (Figure 1), which aligns with the distribution of junior designers with 1-5 years of experience of 46.2 per cent (Figure 2). The sample of junior designers is much younger than the general demographic, with a mean within the 25-34-year range.

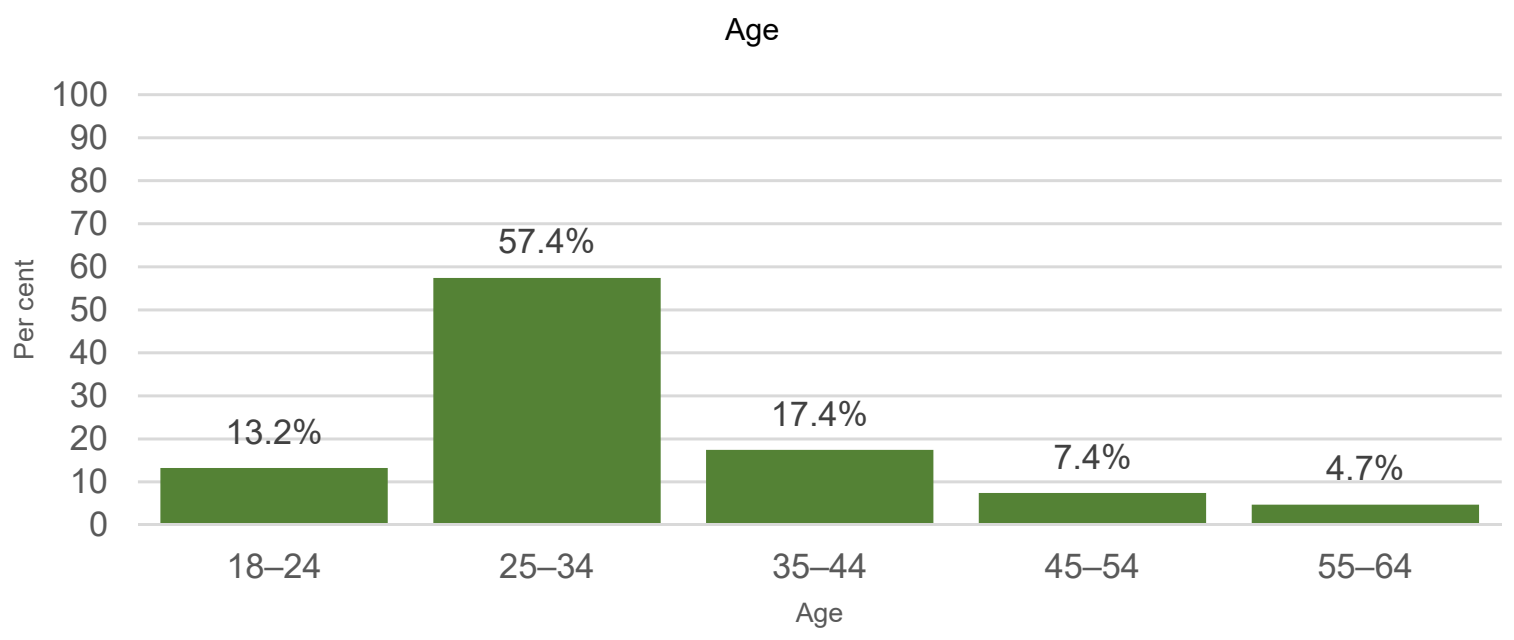

Figure 1. Age in \%.

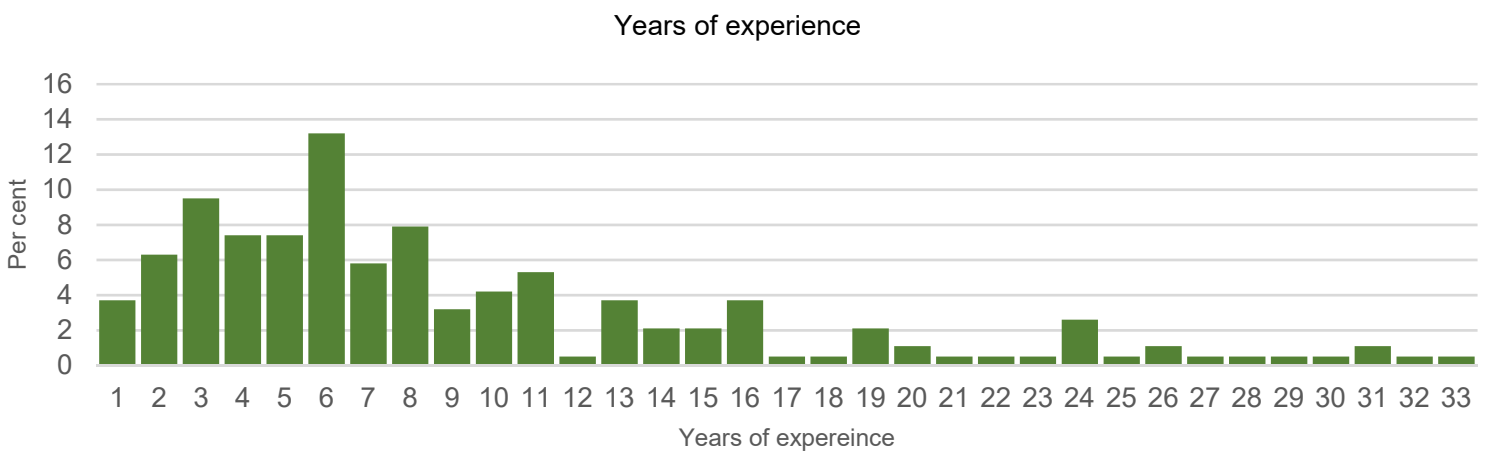

Figure 2. Years of experience in \%.

When examining the years of experience (Figure 2) in the industrial design field a clear trend emerges. The distribution of the respondent's years of experience is skewed to the right. Most of the industrial designers who responded to the survey sit within the 
$0-10$ years of the experience-range. This is seen as a positive as the data have been able to capture emerging industrial designers who will be the ones with the greatest influence for industrial design to adapt to an Industry 4.0 manufacturing paradigm.

The data were also split into four distinct categories to better distinguish between experience levels (Figure 3). Students with no experience make up the lowest percentage of the overall data set with 4.2 per cent $(n=8)$. Since they do not practice industrial design on a professional level, they were therefore omitted from further inferential analysis using one-way ANOVAs, which are tests to find out if certain data are significant. Spearman's Rho and chi-square tests-other tests to test the significance of data-were also applied to test the significance of this data.

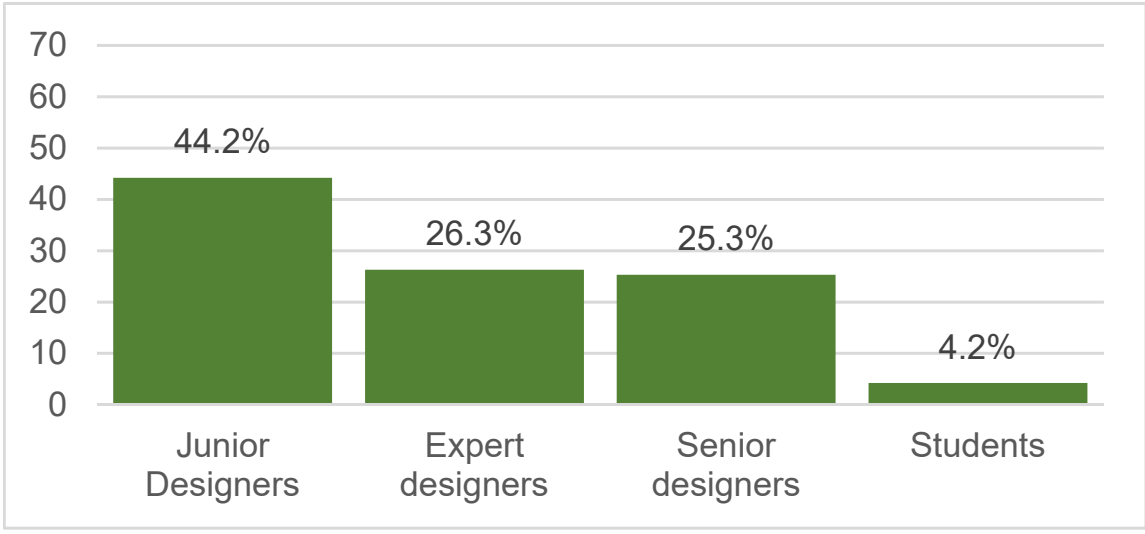

Figure 3. Expert level (in \%).

To obtain a more holistic understanding about industrial design practice globally, data from all continents were gathered, with some countries such as the United States (16.8\%), Australia (10.5\%), France (7.9\%), Germany (5.3\%), Russia (4.7\%) and the UK (4.2\%) being the most prominent countries represented. There was an obvious bias toward Australian respondents since the study was heavily advertised in Australian networks by the authors, however, when sorting the distribution of a respondent's country of origin into continents, the distribution of respondents according to continents became clearer (Figure 4).

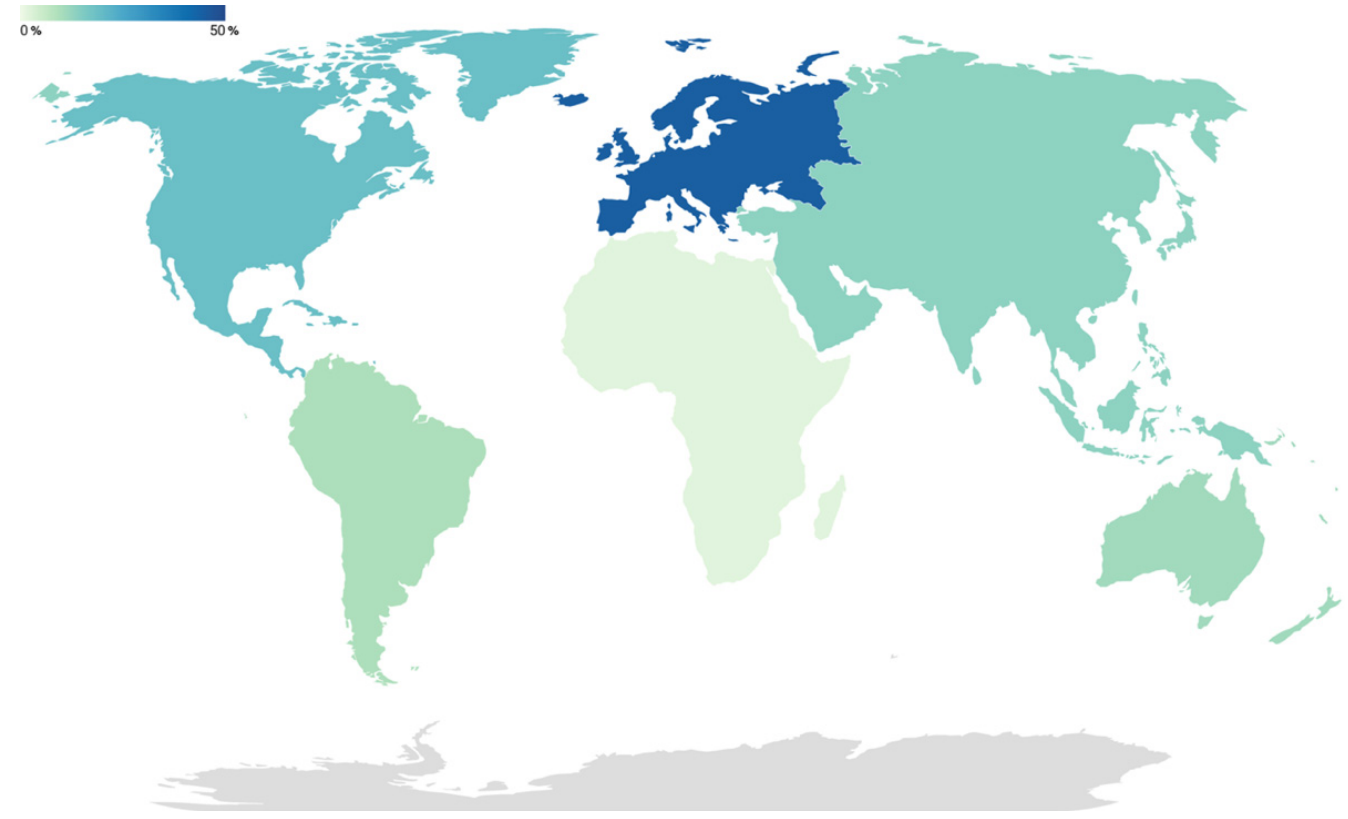

Figure 4. Continent coded by country of origin (in \%). Darker colour = higher distribution. 
- $\quad$ European industrial designers made up the biggest part of the sample with 44.7 per cent $(n=85)$;

- $\quad$ North America with 18.9 per cent $(n=36)$;

- $\quad$ Asia with 13.7 per cent $(n=26)$;

- Australia and Oceania with 11.1 per cent $(n=21)$;

- South America with 9.5 per cent $(n=18)$;

- Africa with 2.1 per cent $(n=4)$;

\section{Results}

The aim of the survey was to obtain a thorough understanding of the industrial design profession globally and its connection to manufacturing. Additionally, the survey has served in understanding whether industrial design professionals know about, and/or already engage with Industry 4.0 technologies and the impact that has on sustainability. Since an overall snapshot of the current state of the profession helps to determine the profession as a whole, close-ended questions were chosen to be analysed via statistical methods. Some questions expanded with subsequent open-ended questions to gain a deeper understanding into a specific topic which may arise during the data analysis.

A repeated measures ANOVA was conducted for multiple answer questions to find the overall highest ranked answer regarding the importance in the design practice of industrial designers (Figure 5). The "importance" indicator was determined by ranking multiple industrial design activities against each other to provide a level of hierarchy specific to the individual. This question asked, "Where do you rank the importance of the following in regard to your design practice?" Product ergonomics and usability was the most highly ranked with a mean of 84.868 , followed by product safety (mean 79.784), material choice (mean 74.768) and manufacturing process (mean 71.668). The lowest ranked aspects presented in the accompanying list were sustainability (mean 67.368), money and pricing (mean 67.153) social responsibility (mean 65.137) and lastly working conditions with a mean of 63.3. Respondents were asked to rank all categories for level of importance; thus, the mean value is the average result for all 190 completed surveys.

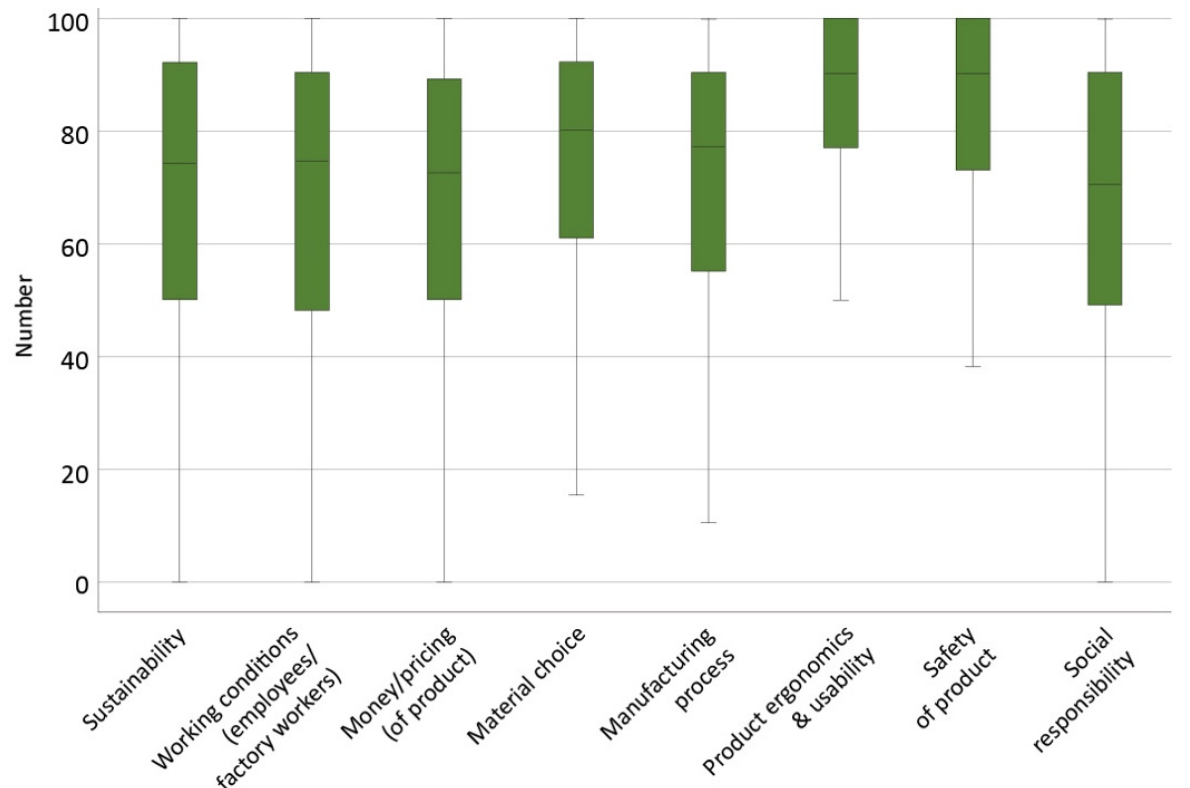

Figure 5. Boxplot: Where do you rank the importance of the following in regard to your design practice? (in \%).

Age, gender and geographic origin had no significant influence on these choices. However, when looking at the experience level of the participating industrial designers one statistically significant association can be found $(p=0.037)$. There is a mean difference 
of 12.46238 in between junior designers and expert designers when looking at the choice of sustainability. That means the expert designers with $10+$ years of experience prioritise sustainability more than junior designers with $<5$ years of experience. A similar trend can be observed with the same variable, sustainability, when looking at whether manufacturing and engineering experience has an effect in the ranking of certain choices. The one-way ANOVA found a statistically substantial association with a $p$ value of 0.039 : industrial designers with experience in the manufacturing and engineering fields prioritised sustainability much higher than practitioners without that same experience (mean 75.7750, SD 24.65712). However, only 21.1 per cent of the surveyed product/industrial designers said they had worked in the manufacturing or engineering field before becoming an industrial/product designer.

Age seems to have a bearing over whether industrial designers had work experience within the manufacturing and engineering field before becoming an industrial designer. The chi-square test showed that the younger designers (age brackets: 18-24, 25-34 and 35-44) have overwhelmingly less manufacturing and engineering experience compared to older industrial designers $(p=0.017)$ (Table 1$)$.

Table 1. Chi-square test: manufacturing or engineering experience by age.

\begin{tabular}{|c|c|c|c|c|c|c|}
\hline & & \multicolumn{5}{|c|}{ What Is Your Age? } \\
\hline & & $18-24$ & $25-34$ & $35-44$ & $45-54$ & $55-64$ \\
\hline \multirow{2}{*}{$\begin{array}{l}\text { Have you worked in the manufacturing or engineering field before } \\
\text { becoming an industrial/product designer? }\end{array}$} & Yes & 5 & 19 & 5 & 6 & 5 \\
\hline & No & 20 & 90 & 28 & 8 & 4 \\
\hline Total & & 25 & 109 & 33 & 14 & 9 \\
\hline
\end{tabular}

It is therefore supported that the experience level and length of practice of an industrial designer correlates with the level of importance given to sustainability. Several one-way between group analyses of variance (ANOVAs), with Fisher's least significant difference (LSD) post hoc tests, were conducted to investigate differences across continents in the variables of interest. There were no significant differences for importance of working conditions, material choice, manufacturing process, ergonomics and usability, safety of product and social responsibility. However, there were significant continental differences (by country of residence or work) for the importance of sustainability $(p=0.040)$ and importance of money/pricing of a product $(p=0.047)$.

North America $(n=40)$ (mean 55.5750) scored significantly lower than Europe $(n=76)$ (mean 72.4342) $(p=0.003)$ and South America $(n=11)($ mean 76.2727) $(p=0.035)$ on the variable: sustainability $(p=0.04)$. This shows that North American industrial designers prioritised sustainability much less than the professionals from Europe and South America (Figure 6). There were no other significant differences between the other continents for this variable.

While the level of importance given to sustainability by junior industrial designers ranked lower than other categories, the open-ended questions revealed overwhelming support for improved sustainability practices. Respondents were asked what changes they would wish to see being implemented in the product/industrial design practice in the future in 50 words or less. The most common theme identified was an increased focus on considering sustainability in the process of design. Industrial designers frequently mentioned the desire for improved sustainable processes, for the improved choice of materials, as well as developing products with longer lifecycles to decrease the negative environmental impact that both manufacturing and disposable items have on the environment. Sustainability was also mentioned in connection to business models as a gateway to responsible design solutions, which rely on material and process innovations rather than in the creation of "short shelf life" goods. The respondents recognised that the current paradigm of consumerism in a world of climate change is not appropriate anymore. They suggested the development of longer lasting products, which would decrease the impact of 
mass-consumption, and they also suggested implementing higher quality designs, with reusable parts, and/or with greater facility for recycling as a way of moving towards a circular economy.

Where do you rank the importance of the following in regard to your design practice? (in \%)

\section{Sustainability by country of residence or work (by continent)}

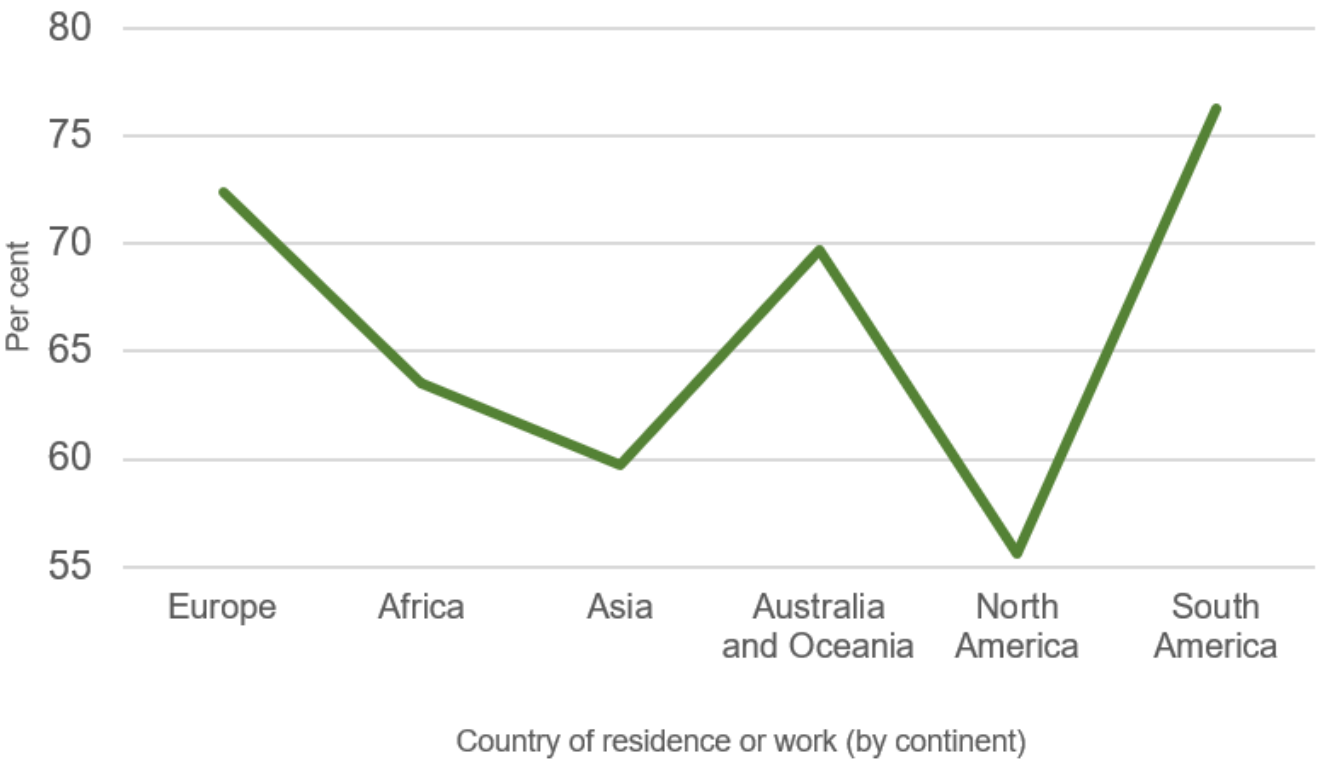

Figure 6. Means plot: sustainability ranked by country of residence or work (by continent).

The desire for less resources and for creating fewer products was stated relatively often. Industrial designers demonstrated a certain sense of responsibility and respect for the environment and a concern to ensure it is a sustainable place for the future. Most industrial designers wish for the initiation for these changes to come from the manufacturing companies rather than from themselves. Besides the responsibility for the natural environment, industrial designers also feel accountable for the working conditions, the rights and the money regulations, as well as being responsible for the sourcing of materials and supplies in the process of a design project.

Therefore, we have found a mismatch of what current industrial designers practice (especially junior designers), with how they would like to practice in the future. This is where greater connection between industrial design and Industry 4.0 can facilitate manufacturing change by supporting more sustainable industrial design outcomes. The digital aspect of Industry 4.0 was also recognised, allowing for interconnection or hyper-connection between machines, the Internet, and people, and thus facilitating better manufacturing processes. Industry 4.0 was frequently described as a solution, which would involve less human intervention in the manufacturing process by incorporating automated and smart systems instead. Simultaneously, the interconnections between humans and machines were a prominent theme - looking at the variety of connections and interface opportunities between the biological (human) and physical (machine).

Respondent \#74, male, United Kingdom:

"The ease of exchanging information, inter connectivity, advanced technology influencing design."

Respondent \#135, male, Russia:

"Smart factory, IoT, Machine learning, AI."

However, this interconnection was not limited to these two domains. Connection was seen in a largely holistic way in which "everything" is linked. Consequently, the factory will not be seen as a separate entity anymore. Industry 4.0 was also seen as an improvement 
to the current manufacturing paradigm, where production efficiency and sustainability is increased, and costs are lowered. Industry 4.0 aspects such as society, the economic context and the environment surrounds were touched on. However, most of the definitions were centred around the physical factory and its production and the organisational structures within it. Designing — as well as the role of the industrial design professional—was not explicitly mentioned. Although it was implied that "designing" would become easier if it was linked to technologies such as additive manufacturing and improvements in AI.

Both the industrial designer and their manufacturing clients/partners are interested in efficiency and improvement within manufacture. This includes cost, time and waste reduction:

Respondent \#52, male, Italy:

"Streamlining processes, avoiding conflicts and improving efficiency."

Respondents frequently discussed sustainability issues for a question that asked, "What changes would you wish to see being implemented in the product/industrial design process in the future?" Sustainability was seen as an improvement rather than a limitation when it came to manufacturing and material selection.

Respondent \#78, male, USA:

"Reducing material consumption and waste while increasing strength and function by creating multi-feature injection molded plastic parts."

Several industrial designers responded wanting to make the world a better place and change people's lives. There was an overwhelming consensus that being an industrial designer comes with a certain obligation to serve people and society, while ensuring sustainability is at the forefront of all design activity. Alarmingly, this does not seem as high of a priority for junior designers (1-5 years of experience) to that of experienced designers (10+ years of experience). Conclusions can be drawn that with experience comes a better understanding of the impact of the profession, therefore, a greater awareness of sustainable design over time. In addition, as skills develop with professional experience, greater efficiencies can be made in both the act of designing, as well as design for manufacture and production. It is with this that Industry 4.0 can play a critical role in enabling a more sustainable manufacturing environment for designers to design for.

Although the priority of improving efficiency and processes highlighted in the survey was typically associated with manufacturers, industrial designers shared their concerns and adapted to the concerns of the production-based stakeholder to be a crucial part in developing their capabilities. This includes cost and time savings in the manufacturing process, as well as waste reduction. The latter aspect aligns with the desire to become more sustainable within manufacturing for new product development.

Respondent \#109, male, USA:

"I wish we had the luxury of business as usual. But in a world where the future of our children - and all the species we share the planet with - are at extreme risk. Design can only be viewed as our last best hope to save the planet."

Some respondents demanded that their career be more ethical and sustainable. However, the majority of the surveyed industrial designers demonstrated a forward-thinking attitude by treating their job and their work in design with integrity and conscience. A respondent concluded this aspect concisely by describing the industrial design profession as:

Respondent \#106, male, USA:

"A holistic methodology by which products are created and/or optimized to address the needs of the user, the manufacturer, and the environment."

Despite this strong statement, industrial designers admitted to feeling powerless when working in the current economic and manufacturing paradigm. There are ethical issues within this system that pose a risk to how much control designers can exercise within this new paradigm. Reference [29] suggests that the increased automation within Industry 4.0 systems remove a level of control; one example can be in the removal of 
humans within manufacturing processes, further distancing designers and operators from engaging with materials to best understand their suitability and sustainability. This distance impacts on the development of tacit knowledge by the designer and operator, and in a way, dehumanises the process. However, the recurring theme of encouraging change for the betterment of existing systems and frameworks within society, as well as the individual, came up regularly. Numerous respondents expressed the desire to "improve people's lives", the quality thereof and/or how the world works around them. Moreover, the meaningfulness of some products and experiences was emphasised. This was due to the longing of industrial designers for purposeful intervention and innovation to create solutions that impacted both consumers and the environment. The response to this desire was defined as innovation. It was believed that innovation could be achieved in a variety of ways to address issues within and outside of the industrial design profession. When it came to positively impacting or enhancing people's lives, innovation and creative processes were frequently reported together.

Pleasingly, improved renewable technology and developing products and goods with longer lifecycles were among the most articulated themes for changes in industrial design practice as ways to minimise the negative environmental impact of both production and disposable objects. It was recognised that the existing consumerism model is no longer suitable in the face of climate change and suggestions were made for the production of longer-lasting goods that reduced mass-consumption and pollution. Industrial design professionals preferred that these improvements were more strongly pushed by manufacturers rather than by themselves. Designers are increasingly engaging with this ethical dilemma [30]; explores this within his research, suggesting that the impact of the finished design-and the ethical consideration of its conception and development-plays an increasingly important role to the consumer, alongside its creative, functional, aesthetic and importantly, sustainable choices.

On a similar note, industrial designers brought up the issue of new manufacturing technologies entering the design field, particularly additive manufacturing (3D printing). These new technologies were heralded as ushering in a new era of manufacturing, freeing industrial designers from the constraints that traditional manufacturing processes impose. This is seen as an enabler for industrial designers to respond to more personalised sustainable products manufactured within an Industry 4.0 paradigm. Moreover, the respondents highlighted that 3D printing is a cheaper alternative to traditional modes of prototyping, which seemed especially important for industrial designers working from home or not having access to a workshop. That means changing the way industrial designers ideate and prototype more effectively in a post-COVID-19 world (where one is forced to work from home), as well as minimising costs, materials and therefore waste. Augmented and virtual reality (AR and VR) technologies were also named concurrently with additive manufacturing. These technologies, however, were described as additional tools for digital prototyping, as well as useful tools for ideation. The need to incorporate these technologies was weaved into discussion on the issues of sustainability in the product development process, since digital ideation (e.g., VR sketching) and prototyping produce no waste (Figure 7).

As stated by [32], new and rapid technological breakthroughs will revolutionise the way industrial designers design, bringing traditional design into the "smart era". Furthermore, the integration of artificial intelligence (AI) with 3D modelling or CAD software was also discussed by the respondents of the survey. The purpose of using digital technologies was to make the overall design and 3D modelling process easier. However, no detailed feedback on how AI would play a role in the product design process and in CAD were provided. Perhaps, AI was confused with processes such as topology optimisation (Figure 8), which is widely used with 3D printed products, allowing new forms to be manufactured that were otherwise impossible to create with traditional ways of mass manufacture, such as injection moulding. 


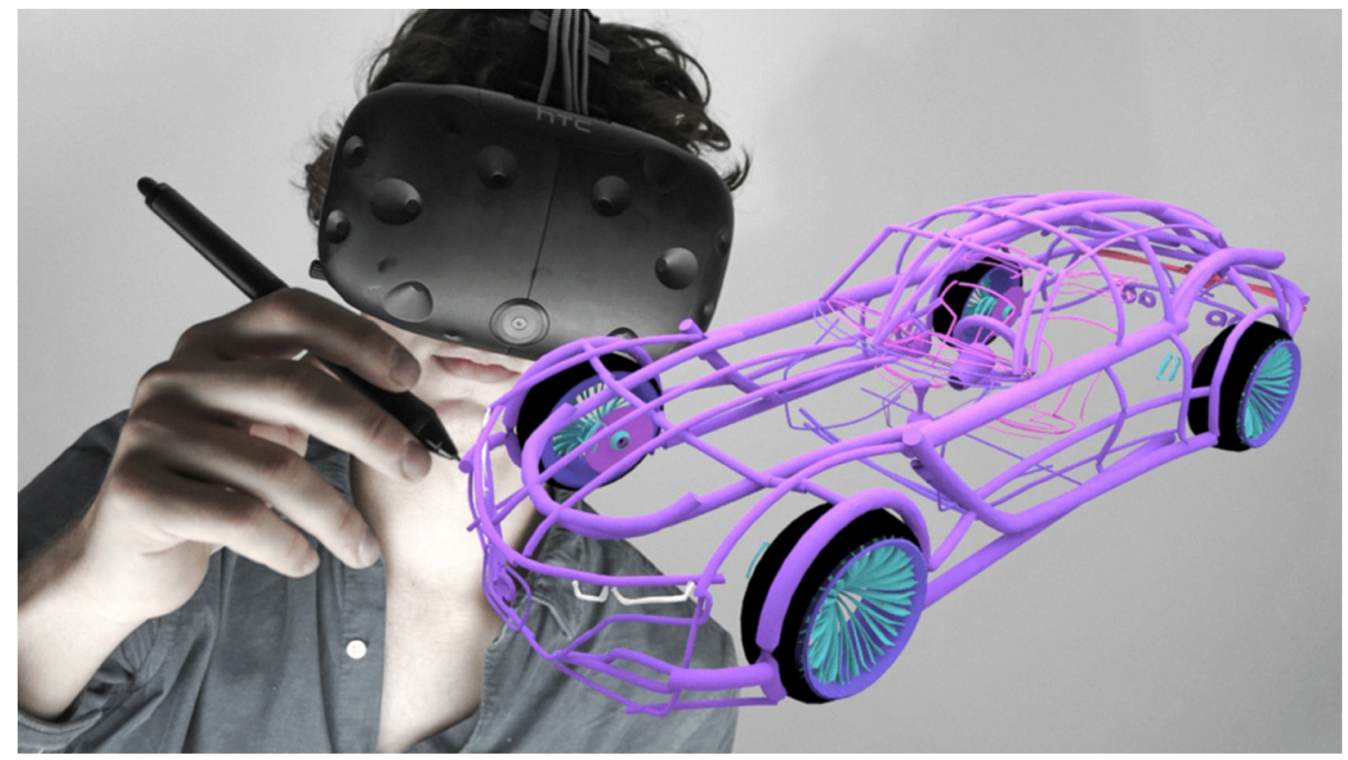

Figure 7. The Gravity Sketch software retrieved from [31].

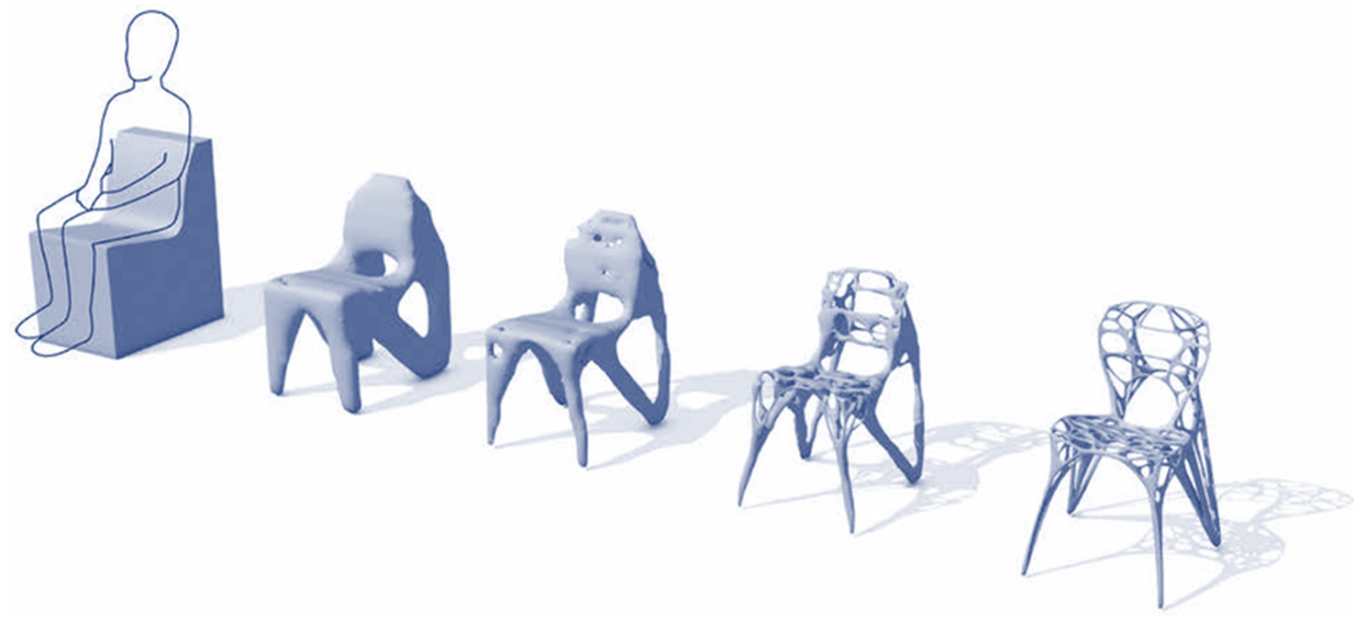

Figure 8. Form-finding process through topology optimization by [33].

Therefore, industrial design and manufacture seem to converge by introducing a new digital sphere, beyond the human and physical ones, that will enable a better connection between both. The findings show that the core-competencies of practitioners remain unchanged, however presented with Industry 4.0 technologies, the state of collaboration and communication with various stakeholders involved in the design and manufacture of products might be transformed. Although the respondents did not make this connection, it is possible that this is the natural progression with both the industrial design and manufacturing fields moving closer together through Industry 4.0. Hence, the physical factory will not be a separate entity anymore but will take on diverse forms. The physicality of the production site might also change as seen with industrial designer's 3D printing their own designs and selling them directly (via websites) as digital model files that can be printed by the customer.

By adopting this decentralised method, industrial designers have the ability to skip multiple steps and stakeholders involved in the processes of developing new products in the traditional manufacturing paradigm. The complexity of supply chains, distribution, marketing etc. is hence reduced. An example for this is seen with LimeLite ${ }^{\circledR}$, which uses unique and complex geometry to create a range of track downlights that can only be manufactured using additive manufacturing (Figure 9). This is because of the undercuts and 
varying wall thicknesses that are impossible to manufacture via traditional manufacturing processes, such as injection moulding [34]. This is an example of an Australian company investing in its own manufacturing facility to avoid having to rely on offshore production and supply chains. In addition, this example demonstrates how important industrial designers are in purposefully designing for novel manufacturing methods to facilitate mass customisation.

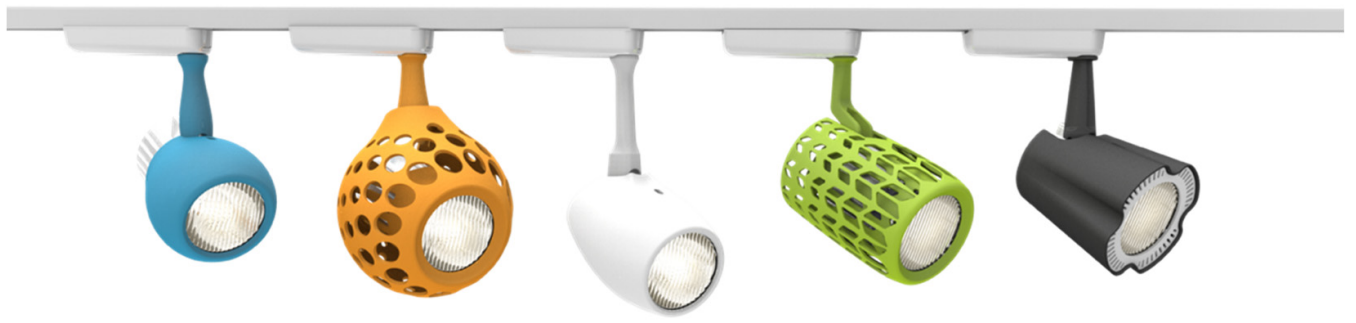

Figure 9. LimeLite ${ }^{\circledR} 3 \mathrm{D}$ printed light fittings by [34].

Digital technologies, as used by LimeLite ${ }^{\circledR}$, enabled industrial designers and individual creators to have more freedom through at-home-manufacture, by directly engaging with the end-user and manufacturer of the product. Although this works well for relatively small quantities, this might not necessarily be applicable for other items. However, the persisting mass-manufacturing paradigm may soon experience its first interruption since its advent. New technologies and systems Industry 4.0 offer might turn this paradigm upside down. Examples such as LimeLite ${ }^{\circledR}$ show that concepts such as mass-customisation within manufacture might further enhance the value of industrial designers within an Industry 4.0 manufacturing environment.

From a sustainability perspective, this is advantageous because there is less risk of products being made that do not sell, wasting valuable resources within production. While 3D printing commercial outcomes is clearly more expensive than the raw cost of an injection moulded part, it is the capital investment required at the front-end of the manufacturing process that is avoided in this situation. While this investment would be amortised across the production run, there is no guarantee the final product will be successful. Crucially, it would avoid a large investment in tooling for mass-production with a risk of an unpopular design languishing on the shelf-with 3D printing it is "print to order".

All listed technologies and methods align with the industrial designer's desire to change and improve the way production, and, by extension, their own practice operates, particularly in terms of sustainability and collaboration. These technologies undeniably represent a paradigm shift in how the fields of industrial design and manufacturing work, as well as how they interact with each other. Although, these technologies currently seem to have a limited adoption as seen in the book Digital Handmade [7], industrial designers appear to be ready and enthusiastic for their further implementation. Many different ideas, aligning with Industry 4.0, were mentioned by the respondents in the survey. Amongst them were concepts such as circular economy, Cradle2Cradle and mass customisation. These terms revolve around the idea of Industry 4.0, as well as relating to different aspects of sustainability in new product development and manufacturing.

\section{Discussion}

The findings showed that the most prominent change industrial designers demanded was for better attention given to issues of sustainability, especially in manufacturing. This was more pronounced for the processes involved in designing for manufacturing, as well as the actual purpose of the products being developed. Industrial designers are aware of the negative impact their designs can have on the environment and indirectly on the people producing and using the products they have designed. Non-recyclable products using unsustainable materials and processes were emphasised, especially in the context of manufacturing. 
Current industrial design practice (especially junior designers) does not regard sustainability as important as other aspects of the discipline such as usability and safety. This is more pronounced from respondents from North America and Asia. Data show a clear disconnect between issues of environmental and social responsibility between industrial designers and their opinion of manufacturers. Whereas industrial designers considered their impact on these issues, manufacturers-in the eyes of the industrial design respondents-were mainly profit and efficiency driven, taking on an introspective approach, compared to the holistic stance of the industrial designers. This may be the reason why sustainability was ranked lower than other aspects of industrial design as practicing industrial designers feel challenged to influence manufacturing. With the emergence of Industry 4.0 we see a trend for industrial designers to work much more closely with their manufacturing counterparts for mutually beneficial, and importantly, sustainable product outcomes. Since industrial designers possess the insight and are critics of the current manufacturing paradigm, they should therefore push manufacturers to adopt more sustainable processes and practices. This would not only benefit the industrial designers in their agendas to incorporate more sustainability in manufacturing processes but could also enable manufacturers to future-proof their businesses and operations in a world where access to resources, labour, and a stable climate, as well as a stable economy is not guaranteed.

Industrial designers felt bad about being indirectly responsible for the design and advancements of mass production of low-quality products-often with a short shelf life. The findings indicate that most surveyed industrial designers disagreed with the current market/manufacturing paradigm and the inherent consequences of mass-consumerism on people and the environment. There was a desire among industrial designers to create longer-lasting, higher quality products that benefit society, humanity, and the environment. The profession which emerged from the advent of mass manufacture, now has the chance to become more than what its name suggests. This trend shows the changes manufacturing has undergone and the opportunity for more personalised sustainable products as we enter an Industry 4.0 manufacturing paradigm.

Industry 4.0 is being hailed as the new paradigm in the manufacture of products and has areas of development which overlap with the changes demanded by industrial designers. The findings suggest that industrial designers, in their desires to create longer lasting and sustainable products, are ahead of the current manufacturers. However, the data only considered the view of industrial designers and future research must be performed to better understand the view of manufacturers. Changes such as sustainability and longer lasting products, as demanded from industrial designers, are dependent on the willingness of manufacturers to incorporate such changes. Implementing such radical changes depends on a multitude of factors, such as the inclination of the market to adopt certain practices and on policy makers to implement laws and frameworks to incentivise a circular economy, slowly stepping away from the mass-consumption paradigm of the 20th century.

Guidelines for Industry 4.0 implementation, in general, are driven by government programs with the core idea of Industry 4.0 using emerging technologies in a way that business processes are deeply integrated, making production operate in a flexible, efficient and sustainable way [35]. From a design perspective, we have seen a shift to more complex systems bought on by an increased need on human centred design [36]. Thus, the shift in design needs to align with the shift in manufacturing. Knowledge from design practitioners is critical to ascertain greater understanding of design and its connection to Industry 4.0 and how this will change the way industrial designers approach the complexity of sustainability. From an academic point of view to our knowledge, this is the first time practicing industrial designers have been surveyed to understand the present state of industrial design practice globally, its connection to Industry 4.0, and the priority given to sustainability in this new manufacturing paradigm. We have found that junior industrial designers do not currently see sustainability as a priority, establishing a foundation for future research to understand why this is the case. It is the position of the authors that as Industry 4.0 begins 
to become the dominant manufacturing paradigm, education and engagement with ethical and sustainable practices need to be expanded. This ensures that the tacit knowledge of materiality and manufacture is maintained, despite the potential disconnect between computer-aided design and the highly automated production process.

\section{Conclusions}

The research indicated several problematic and/or distinctive aspects of the industrial design profession. Industrial designers immerse themselves in the responsibilities of both production stakeholders and end-users when working on projects. Moreover, industrial designers think they have a clear commitment to people and the world regarding social equality and sustainability. This displays a true vision as well as a profound comprehension of the interactions between humans and the environment. Meaningful and creative pursuits appear to be immensely satisfying in both the respondents' professional and personal lives.

Reference [6] predicted the post-industrial design field to be more inclusive and flexible, allowing for the dissolution of hierarchical structures within product development. The data from the survey, conversely, suggest that the post-industrial design paradigm has not yet been reached. Nonetheless, the incorporation of digital technologies allows for increased collaboration between industrial designers and production-based stakeholders which might lead to this prediction becoming a reality. An additional point confirming [6] was the demand for an increased social and ecological environmental consciousness by practitioners and a greater sense of responsibility. The data from the survey supported a strong need to reform sustainable practices and products and questioned the values of the existing mass-manufacturing paradigm. Many of the points raised by [6] align with the novel manufacturing paradigm, especially the one about short-run and customised production. Whether the mass-manufacture paradigm will completely change remains uncertain, based on the data gathered.

The industrial design and manufacturing fields co-evolved since the first industrial revolution and are dependent on each other. The statement by [5] about designers not being able to adapt would lead to new abilities, remains valid but given that Industry 4.0 is still in its early stages it is unclear what those gaps are.

There has been limited fundamental reinvention of design practice in order to play an active role in the culture of sustainability, highlighting no clear paths to new forms of practice [13]. Although a paper by [37]—along with others [38]—are improving this, considerable work is still required. Younger designers need to feel empowered to prioritise sustainability. With the emergence of Industry 4.0 industrial designers have an increased ability to work with modern manufacturing in a manner that is sustainable, efficient and importantly, profitable. These drivers for both industrial designers and manufacturers need to co-create to allow innovation to mature in a manufacturing environment that is radically different to that of the dirty factory in which industrial design got its name.

Refs [39-41], amongst others, are exposing students to a deeper understanding of sustainable design principles, by considering products and systems that promote community cohesiveness, enable user participation, help overcome barriers to sustainable behaviours and reduce lifecycle impacts [39]. To future-proof industrial design, increased educational awareness about the ethical and sustainable impacts of Industry 4.0 within the discipline is required which is evident in this study. We have found that sustainable priorities seem to come through experience in practice, rather than experience at university. Therefore, the design curriculums in universities need to be adjusted, taking into consideration the ever-changing techno-cultural environment of industry, manufacturing, and design. Although the core values of industrial designers remain largely unchanged, their sustainability literacy needs to be improved upon. This is also important for technological literacy with new digital technologies entering the manufacturing field as projected with Industry 4.0 .

To be an industrial designer is empowering. Industrial designers drive innovation capabilities within organisations and have a unique capacity to push manufacturing bound- 
aries and challenge current and established paradigms. This paper confirms the importance of the industrial design discipline and the significant value it offers for manufacturing. It shows the moral and social responsibility an industrial designer has for sustainability but greater awareness of this needs to be passed on to junior designers. Manufacturers need skilled industrial designers to drive innovation. Industrial designers need advanced manufacturers to turn their good ideas into tangible outcomes. Without an established strong connection between both, they would struggle to innovate and compete on a global platform.

Author Contributions: Conceptualisation, B.K.; methodology, C.K.; validation, B.K. and C.K; formal analysis, C.K.; investigation, B.K., C.K. and G.R.; resources, B.K. and C.K.; writing-original draft preparation, B.K.; writing-review and editing, B.K., C.K. and G.R.; visualization, C.K.; supervision, B.K. and G.R.; project administration, B.K.; funding acquisition, B.K. All authors have read and agreed to the published version of the manuscript.

Funding: This research was supported by Swinburne University Postgraduate Research Award.

Institutional Review Board Statement: The study was conducted according to the guidelines of the Declaration of Helsinki and approved by the Ethics Committee of Swinburne University of Technology (protocol code 20201591-3554 approved May 2019).

Informed Consent Statement: Informed consent was obtained from all subjects involved in the study as per the approved ethical protocol described in Section 3 (Method).

Data Availability Statement: The data presented in this study are available on request from the corresponding author. The data are not publicly available due to approved ethical restrictions.

Acknowledgments: This study was derived from Christoph Koch's PhD thesis supported by a Swinburne University Postgraduate Research Award scholarship. We thank Swinburne University of Technology for providing this scholarship. We also thank the research respondents for their time and cooperation, along with the editor and reviewers of this paper.

Conflicts of Interest: The authors declare no conflict of interest.

\section{References}

1. Kozma, D.; Varga, P.; Soos, G. Supporting Digital Production, Product Lifecycle and Supply Chain Management in Industry 4.0 by the Arrowhead Framework-A Survey. In Proceedings of the 2019 IEEE 17th International Conference on Industrial Informatics (INDIN), Helsinki, Finland, 22-25 July 2019.

2. Jamwal, A.; Agrawal, R.; Sharma, M.; Kumar, V.; Kumar, S. Developing A sustainability framework for Industry 4.0. In Proceedings of the 28th CIRP Conference on Life Cycle Engineering, Jaipur, India, 10-12 March 2021.

3. Habib, M.K.; Chimsom, C. Industry 4.0: Sustainability and Design Principles. In Proceedings of the 20th International Conference on Research and Education in Mechatronics (REM), Wels, Austria, 23-24 May 2019.

4. Garcia Ferrari, T. Design and the Fourth Industrial Revolution. Dangers and opportunities for a mutating discipline. Des. J. 2017, 20, S2625-S2633. [CrossRef]

5. Heskett, J. Past, Present, and Future in Design for Industry. Des. Issues 2001, 17, 18-26. [CrossRef]

6. Cross, N. The coming of post-industrial design. Des. Stud. 1981, 2, 3-7. [CrossRef]

7. Johnston, L. Digital Handmade: Craftsmanship in the New Industrial Revolution; Thames \& Hudson: London, UK, 2017.

8. Franzato, C. Open Design for Industry 4.0. MD J. 2017, 4, 26-39.

9. Manzini, E. Design, When Everybody Designs: An Introduction to Design for Social Innovation; MIT Press: Cambridge, MA, USA, 2015; ISBN 026232864X.

10. Fuller, D.; Ottman, J. Moderating unintended pollution: The role of sustainable product design. J. Bus. Res. 2004, 57, 1231-1238. [CrossRef]

11. Koren, Y. The Global Manufacturing Revolution Product-Process-Business Integration and Reconfigurable Systems; Wiley: Hoboken, NJ, USA, 2010.

12. Cuffaro, D.; Sears, L.M.; Nehez-Cuffaro, A.; Zaks, I.; Covert, D.E.; Paige, D.; Blackman, C.J.; Laituri, D. The Industrial Design Reference + Specification Book: All the Details Industrial Designers Need to Know but Can Never Find; Rockport Publishers: Beverly, MA, USA, 2013.

13. Margolin, V. Design for a sustainable world. Des. Issues 1998, 14, 83-92. [CrossRef]

14. Papanek, V. Design for the Real World: Human Ecology and Social Change; Academy Chicago Publishers: Chicago, IL, USA, 1972.

15. Kuys, J.; Al Mahmud, A.; Kuys, B. A Case Study of University-Industry Collaboration for Sustainable Furniture Design. Sustainability 2021, 13, 10915. [CrossRef] 
16. Rayna, T.; Striukova, L.; Darlington, J. Co-creation and user innovation: The role of online 3D printing platforms. J. Eng. Technol. Manag. 2015, 37, 90-102. [CrossRef]

17. Mourtzis, D.; Doukas, M.; Psarommatis, F. Design and operation of manufacturing networks for mass customization. CIRP Ann. 2013, 62, 467-470. [CrossRef]

18. Tseng, M.M.; Jiao, J.; Merchant, M.E. Design for Mass Customization. CIRP Ann. 1996, 45, 153-156. [CrossRef]

19. Pei, E.; Campbell, I.; Evans, M. A Taxonomic Classification of Visual Design Representations Used by Industrial Designers and Engineering Designers. Des. J. 2015, 14, 64-91. [CrossRef]

20. Wilson, S.; Zamberlan, L. Design for an Unknown Future: Amplified Roles for Collaboration, New Design Knowledge, and Creativity. Des. Issues 2015, 31, 3-15. [CrossRef]

21. Buchanan, R. Wicked Problems in Design Thinking. Des. Issues 1992, 8, 5-21. [CrossRef]

22. Friedman, K. Theory construction in design research: Criteria: Approaches, and methods. Des. Stud. 2003, 24, 507-522. [CrossRef]

23. Campbell, R.I.; Hague, R.J.; Sener, B.; Wormald, P.W. The Potential for the Bespoke Industrial Designer. Des. J. 2003, 6, 24-34. [CrossRef]

24. Garcia-Muiña, F.; González-Sánchez, R.; Ferrari, A.M.; Volpi, L.; Pini, M.; Siligardi, C.; Settembre-Blundo, D. Identifying the Equilibrium Point between Sustainability Goals and Circular Economy Practices in an Industry 4.0 Manufacturing Context Using Eco-Design. Soc. Sci. 2019, 8, 241. [CrossRef]

25. Tang, M.; Liao, H.; Wan, Z.; Herrera-Viedma, E.; Rosen, M. Ten Years of Sustainability (2009 to 2018): A Bibliometric Overview. Sustainability 2018, 10, 1655. [CrossRef]

26. Yang, M.; Vladimirova, D.; Evans, S. Creating and Capturing Value Through Sustainability. Res.-Technol. Manag. 2017, 60, 30-39. [CrossRef]

27. Bocken, N.M.P.; Short, S.W.; Rana, P.; Evans, S. A literature and practice review to develop sustainable business model archetypes J. Clean. Prod. 2014, 65, 42-56. [CrossRef]

28. Koch, C.; Kuys, B.; Renda, G. A pilot study used to better construct a research direction to understand where industrial design fits within the 4th industrial revolution (Industry 4.0). In Proceedings of the Synergy-DRS International Conference 2020, Online, 11-14 August 2020; Boess, S., Cheung, M., Cain, R., Eds.; [CrossRef]

29. Trentesaux, D.; Caillaud, E. Ethical stakes of Industry 4.0. In Proceedings of the 21st IFAC World Congress, Berlin, Germany, 12-17 July 2020.

30. Becker, C.U. Ethical Principles for Design in the 21st Century. SSRN 2021, 1-17. [CrossRef]

31. Morby, A. Gravity Sketch Software. Dezeen.com. 2017. Available online: www.dezeen.com/2017/01/13/gravity-sketch-virtualreality-vr-software-creative-professionals-launches-beta-testing-platform-design-technology/ (accessed on 3 September 2021).

32. Zhong, R.Y.; Xu, X.; Klotz, E.; Newman, S.T. Intelligent Manufacturing in the Context of Industry 4.0: A Review. Engineering 2017, 3, 616-630. [CrossRef]

33. Hemmerling, M.; Nether, U. Generico: A case study on performance-based design. In Proceedings of the XVIII Conference of the Iberoamerican Society of Digital Graphics-SIGraDi: Design in Freedom, Universidad de la Republica, Montevideo, Uruguay, 12-14 November 2014

34. Kuys, B.; Strachan, M. The inherent value of design research for industry: An impact case study using low-cost 3D printing for high-value commercial products. In Proceedings of the Synergy_DRS International Conference 2020, Online, 11-14 August 2020; Boess, S., Cheung, M., Cain, R., Eds.; [CrossRef]

35. Machado, C.G.; Winroth, M.P.; Ribeiro da Silva EH, D. Sustainable manufacturing in Industry 4.0: An emerging research agenda. Int. J. Prod. Res. 2020, 58, 1462-1484. [CrossRef]

36. Ceschin, F.; Gaziulusoy, I. Evolution of design for sustainability: From product design to design for system innovations and transitions. Des. Stud. 2016, 47, 118-163. [CrossRef]

37. Diehl, J.; Boks, C.; Silvester, S. The Evolution of Design for Sustainability Courses. In Proceedings of the 2005 4th International Symposium on Environmentally Conscious Design and Inverse Manufacturing, Tokyo, Japan, 12-14 December 2005.

38. Boks, C.; Diehl, J. Integration of sustainability in regular courses: Experiences in industrial design engineering. J. Clean. Prod. 2006, 14, 932-939. [CrossRef]

39. Ramirez, M. Promoting Sustainability through Industrial Design Studio Projects. In Proceedings of the Connected 2007 International Conference on Design Education, Sydney, Australia, 9-12 July 2007.

40. Kuys, B.; Velasquez Montoya, M.; Thong, C.; Glover, J. Embedding sustainability in product design engineering curriculum: A comparison of needs on an international level. In Proceedings of the Design Research Society Conference, Bangkok, Thailand, 1-4 July 2012.

41. Deniz, D. Sustainable Thinking and Environmental Awareness through Design Education. Procedia Env. Sci. 2016, 34, 70-79. [CrossRef] 